\title{
IMPAIRED FOREARM BLOOD FLOW RESPONSE TO BREATH HOLDING IN DIABETIC PATIENTS WITH MANIFESTATIONS OF NEUROPATHY
}

\author{
Yoseph A. Mengesha \\ Department of Physiology, Faculty of Medicine, Addis Ababa University \\ PO Box 9086, Addis Ababa, Ethiopia
}

\begin{abstract}
Breath holding affects vasomotion through an increase in $\mathrm{PaCO}_{2}$ and a decrease in $\mathrm{PaO}_{2}$ and intrathoracic pressure in normal subjects. This study attempts to see if the vasomotivese response would be the same in persons with diabetic autonomic neuropathy. Seven healthy subjects (one female and six males, fasting blood sugar, 4.44-5.83 mmol L-1 and aged 45-55 years) and seven diabetics (one female and six males, fasting blood sugar, 5.00-7.78 $\mathrm{mmol} \mathrm{L}^{-1}$ and aged 45-57 years) were studied while breathing normally for about five minutes and during a breath holding period of 40-65 seconds. Four to five readings were recorded in each testing condition with a resting interval of about 90 seconds. The overall mean forearm blood flow decreased significantly $(\% \Delta=\mathbf{- 4 1 . 1 6}$, $P<0.01$ ) in the healthy subjects holding their breath for 40-65 seconds (average $=52.1 \mathrm{sec}$ ). This reduction in forearm blood flow, which was not proportional to the duration of breath holding, signifies the reflex effect of increased $\mathrm{PaCO}_{2}$ and decreased $\mathrm{PaO}_{2}$. None of the diabetic patients showed forearm blood flow reduction in response to an average breath holding time of 51.4 seconds $(\% \Delta=3.56, \mathrm{p}<0.50)$. This lack of reflex vasomotion in response to increased $\mathrm{PaCO}_{2}$ and decreased $\mathrm{PaO}_{2}$ indicates that the sympathetic supply to the vascular bed of the forearm is not intact. The apparent changes in the blood gases occurring during breath holding did not produce a direct vasodilatory effect either. This is probably attributable to vessel wall rigidity and lack or ineffectivity of endothelium-derived factors developing with metabolic and structural derangements. The resting overall mean forearm blood flow in diabetics $(5.33 \pm$ $0.78 \mathrm{ml} / 100 \mathrm{ml} / \mathrm{min})$ compared with that of the controls $(3.96 \pm 0.39 \mathrm{ml} / 100 \mathrm{ml}-$ $/ \mathrm{min})$ is significantly greater $(\% \Delta=+36.62, \mathrm{p}<0.01)$. This apparently suggests that diabetic neuropathy leads to elevated resting blood flow. The significance of the present finding is that breath holding can be used as a quick method for
\end{abstract}


assessing sympathetic denervation by measuring forearm blood flow and related cardiovascular variables.

\section{Key words/phrases: Breath holding, forearm blood flow, diabetic- neuropathy}

\section{INTRODUCTION}

In man with normal neurovascular status, the response to a respiratory act like breath holding is brought about by chemical and mechanical factors both of which feed into reflex pathways (Godfrey and Campell, 1968). Normally cardiac output and forearm blood flow measured/during breath holding are affected by increase in $\mathrm{PaCO}_{2}$, decrease in $\mathrm{PaO}_{2}$ and by mechanical changes in the pulmonary, thoracic and abdominal regions. The increase in $\mathrm{PaCO}_{2}$ is attributable to the concentrating effect of lung volume shrinkage and the failure of clearance of $\mathrm{CO}_{2}$ from venous blood during breath holding (Mithoefer, 1959). The mechanical changes including a decrease in intrathoracic pressure and lung volume shrinkage are caused by upward movement of the diaphragm (Agostoni, 1963). These changes are probably signalled to motor pathways in the respiratory system.

In the first 15-20 seconds of breath holding, the concentration of $\mathrm{CO}_{2}$ in the mixed venous blood remains essentially constant (Dubois et al., 1952). Oxygen uptake remains virtually normal with the arterial content falling concomitantly (Dubois, 1952). In normal subjects, when the duration of breath holding is increased, intrathoracic pressure and lung volume continue to fall (Mithoefer, 1959) and $\mathrm{PaO}_{2}$ decreases while $\mathrm{PaCO}_{2}$ increases (Parving, 1983). Increase in $\mathrm{PaCO}_{2}$ reduces the blood flow through skeletal muscle and increases it through the brain (Lennox and Gibbs, 1932, Ketty and Schmidt, 1948; Kontos et al., 1967). During breath holding, the rise in $\mathrm{PaCO}_{2}$ activates the sympathetic nervous system (Lopez de Pablo et al., 1982; Zhang et al., 1982, Rose et al., 1983; Lioy et al., 1985) and produces vasoconstriction in the limbs. The reduction in intrathoracic pressure contributes to an increase in venous return which eventually leads to an increase in arterial blood pressure via the 
baroreceptor mechanism. Hypoxia has a similar but relatively less significant reflex effect.

The effect of breath holding on the peripheral vascular bed in normal subjects is already established. Paulev (1969) found a forearm blood flow reduction of $68 \%$ and a mean arterial blood pressure increase of $30 \%$ during a one minute breath holding. These cardiovascular changes are attributed to an increase in sympathetic discharge. Whether or not such changes would be completely absent in diabetic patients with neurovascular disorders is not yet established. The circulatory response, if any, is largely a result of local events in diabetic patients with interrupted afferent pathways to or from the vasomotor centre.

It is understood that diabetic patients with manifestations of neuropathy have sympathetic denervation of blood vessels resulting in a decrease in central vasomotor reflexes (Moorhouse et al., 1968), vessel wall rigidity (Munck et al., 1966), capillary basement membrane thickening, atherosclerosis (Eliasson, 1971) and impaired contraction and endothelium-dependent relaxation of resistance vessels (McNally et al., 1994). These changes are a result of metabolic and humoral factors (Parving, 1983) leading to obscurity of vasomotive responses to various testing conditions.

Vascular denervation and metabolic derangements in diabetic patients lead to increased resting blood flow and locally induced vasodilatation. Using venous occlusion plethysmography, Archer et al. (1984) and Gilbey et al. (1986) found that blood flow in the feet of diabetic patients with neuropathy was more than five times the flow in normal controls. Arteriovenous shunts with dilated diameter occur secondary to pathological and metabolic changes to increase the peripheral blood flow very significantly. The release of vascular tone by sympathetic denervation and the development of arteriovenous shunts predominate the possible flow-reducing effect that capillary basement membrane thickening, atherosclerosis (Eliasson, 1971) and vessel wall rigidity (Munck et al., 1966) may produce. In patients with both neural and vascular disorders, effects relating to endothelium-derived factors are lacking (McVeigh et al., 1992; Williams et al., 1996; Avogaro et al., 1997). This hampers vascular responses to agents of vasomotion. The present study is an attempt to assess the 
relative forearm blood flow response to breath holding in diabetic patients with manifestations of neuropathy.

\section{MATERIALS AND METHODS}

Ten consenting diabetic patients were considered for the present study. Seven of them (one male insulin-dependent diabetic, five male and one female noninsulin dependent diabetic, with a fasting blood sugar of 5.00-7.78 $\mathrm{mmol} \mathrm{L}^{-1}$ and aged 45-57 years) with manifestations of neuropathy, were used to study forearm blood flow response to a breath holding of 40-65 seconds duration. The remaining three subjects were rejected for not meeting the criteria stated below. Seven normal subjects (six males and one female, with a fasting blood sugar of 4.44-5.83 mmol L $\mathrm{L}^{-1}$ and aged 45-55 years) were taken as controls. The average duration of breath holding was 52.1 seconds in controls and 51.4 seconds in the diabetic patients. The insulin-dependent diabetic patient had the same signs and symptoms of neuropathy as the other patients and was, therefore included in the present study. The diabetic patients were selected on the basis of: (1) neurological tests showing the presence of burning sensation in the feet and hands, numbness in the limbs, reduced sensation for vibration, (2) sympathetic dysfunction as reflected by inability to maintain arterial blood pressure in a $45^{\circ}$ passive head-up tilt. All subjects were instructed to practice breath holding for some time. Then subjects capable of holding their breath for $40-65$ seconds were included in the investigation.

In the head-up position, diabetics had a fall in arterial blood pressure that was not reversed reflexly. This was done to confirm the findings by other workers (Hilsted, 1978; Singh and Khurana, 1990; Tooke et al., 1990) and to ascertain that the diabetics meet the study criteria. The duration of diabetes (2-14 years) did not correspond to the neurological conditions that each subject had.

The study was carried out in the morning between 9 a.m. and 12 noon with the subject lying on a couch in a room where the temperature ranged between 22 and $23^{\circ} \mathrm{C}$ throughout the study period. Fasting blood sugar was determined prior to flow measurement. Forearm blood flow was measured by venous 
occlusion plethysmography using a Whiteny mercury-in-rubber resistance strain gauge with a balancing unit (Whiteny, 1953) coupled to a Devices set up of preamplifier and pen recorder while the subject was breathing normally and during breath holding. The flow to the hand was occluded at a pressure of about $26.7 \mathrm{kpa}$. Then 4-5 readings of forearm blood flow (Fig. 1) were recorded for about five minutes in each subject with the strain gauge wound on the forearm at a tension of about $15-20 \%$ and with a pneumatic cuff placed on the upper arm at a pressure of about $8 \mathrm{kpa}$ to occlude the venous outflow for about 15 seconds. A nose clip was tightly placed on the nose and the subject was instructed to hold the breath following normal inspiration and with the epiglottis open for as long as he/she could. At the end of flow recording, the girth of the forearm under the strain gauge was measured and the strain gauge calibrated for each subject. The slope value per minute of the inflow curve was multiplied by the calibration factor formulated by Whitney (1953) to approximate the forearm blood flow. Four to five breath holding attempts were made during a testing period of 8-10 minutes with a resting interval of about 90 seconds. One reading was taken during each breath holding.

The readings taken from each subject while breathing normally and during breath holding were averaged in both groups of subjects. The coefficients of variation of the mean forearm blood flow in each testing condition was determined for each subject. Then the overall mean \pm S.E was computed and test of significance performed using the software INSTAT2. Unpaired t-test was used to compare overall means between controls and diabetics.

\section{RESULTS}

The mean forearm blood flow measured during normal breathing and breath holding in both controls and patients with diabetic neuropathy is as shown in Tables 1 and 2. Coefficients of variation calculated for flow readings of both controls and diabetics showed only a small range of intra-individual variations (Tables 1 and 2). The mean resting forearm blood flow was found to be greater in the diabetic patients $(5.33 \pm 0.78 \mathrm{ml} / 100 \mathrm{ml}$ tissue $/ \mathrm{min})$ than it was in the control subjects $(3.96 \pm 0.39 \mathrm{ml} / 100 \mathrm{ml}$ tissue $/ \mathrm{min})$. Breath holding produced 
significant reduction in the forearm blood flow of control subjects $(\% \Delta=$ 41.16) (Fig. 1). In diabetic patients with neuropathy, however, there was no change on breath holding, i.e., the average forearm blood flow measured during breath holding was essentially the same as the forearm blood flow measured during normal breathing (Table 2 and Fig. 2).

Table 1. The effect of breath holding on forearm blood flow $(\mathrm{ml} / 100 \mathrm{ml}$ tissue/min) of normal subjects.

\begin{tabular}{lllllll}
\hline No. & Age & Sex & $\begin{array}{c}\text { FBS } \\
\left(\mathrm{mmol} \mathrm{L}^{-1}\right)\end{array}$ & $\begin{array}{l}\text { FBF during nor- } \\
\text { mal breathing }\end{array}$ & CV,C/T & $\begin{array}{l}\text { FBF holding } \\
\text { during breath }\end{array}$ \\
\hline 1 & 45 & M & 4.72 & $5.2 \pm 0.80$ & $15.39 / 14.29$ & $2.1 \pm 0.30$ \\
2 & 45 & F & 5.83 & $2.9 \pm 0.42$ & $11.03 / 10.00$ & $2.8 \pm 0.28$ \\
3 & 55 & $M$ & 5.00 & $4.8 \pm 0.69$ & $10.21 / 9.55$ & $2.2 \pm 0.21$ \\
4 & 54 & $M$ & 5.72 & $5.1 \pm 0.82$ & $12.16 / 11.08$ & $3.7 \pm 0.41$ \\
5 & 55 & $M$ & 5.28 & $3.4 \pm 0.30$ & $10.29 / 10.83$ & $2.4 \pm 0.26$ \\
6 & 47 & $M$ & 5.56 & $3.5 \pm 0.50$ & $14.29 / 14.09$ & $2.2 \pm 0.31$ \\
7 & 50 & $M$ & 4.44 & $2.8 \pm 0.38$ & $13.57 / 11.25$ & $1.6 \pm 0.18$ \\
$M$ & 51.4 & & 5.04 & 3.96 & & 2.43 \\
SE & & & \pm 0.39 & & \\
MD & & & & 1.53 & \\
\% & & & & 41.16 & \\
P & & & & $<0.01$ & \\
\hline
\end{tabular}

M, Mean; FBS, Fasting blood sugar; FBF, Forearm blood flow; SE, Standard error; $\mathrm{MD}$, Mean difference; $\mathrm{CV}, \mathrm{C} / \mathrm{T}$, Coefficient of variation, control/test; $\% \Delta$, percentage change. 

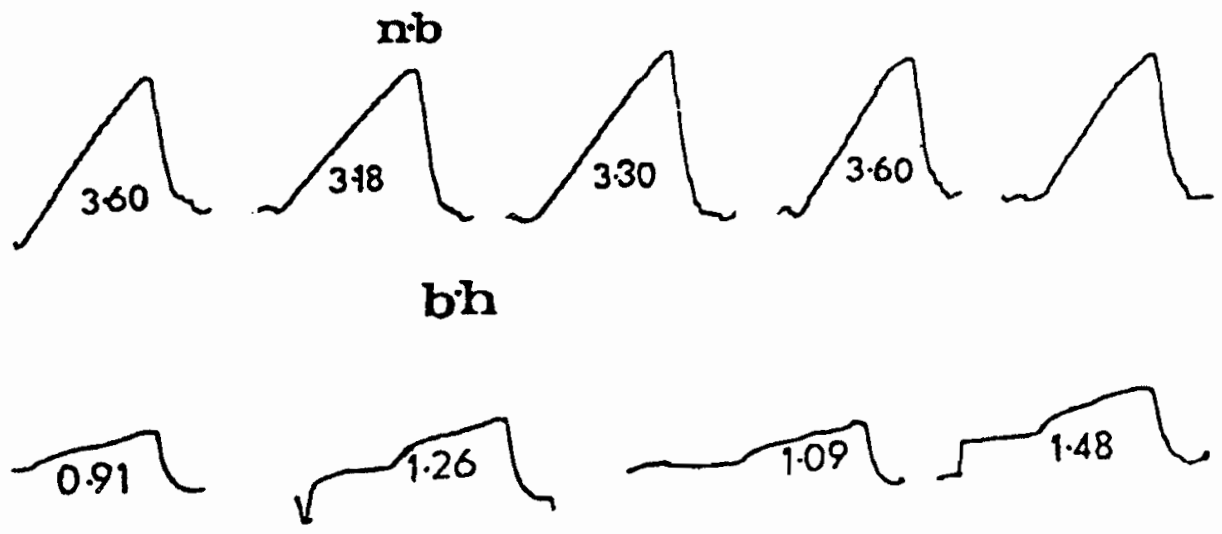

Fig. 1. Forearm inflow curves recorded in a normal subject while breathing normally (nb) and during the last 15 seconds of a 65 -second breath holding (bh) duration.

Table 2. The effect of breath holding on forearm blood flow ( $\mathrm{ml} / 100 \mathrm{ml}$ tissue/min) of diabetic patients.

\begin{tabular}{|c|c|c|c|c|c|c|c|}
\hline No. & $\begin{array}{l}A \\
(y r)\end{array}$ & $\mathbf{s}$ & $\begin{array}{l}\text { Duration of } \\
\text { diabetes (yr) }\end{array}$ & $\begin{array}{c}\text { FBS } \\
\left.(\mathrm{mmol} \mathrm{L})^{-1}\right)\end{array}$ & $\begin{array}{l}\text { FBF during nor- } \\
\text { mal breathing }\end{array}$ & $\mathrm{CV}, \mathrm{C} / \mathrm{T}$ & $\begin{array}{l}\text { FBF during } \\
\text { breath holding }\end{array}$ \\
\hline 1 & 45 & $\mathbf{M}$ & 14 & 7.78 & $7.5 \pm 0.74$ & $9.87 / 8.43$ & $8.9 \pm 0.75$ \\
\hline 2 & 54 & $\mathbf{F}$ & 2 & 5.00 & $3.3 \pm 0.30$ & $9.70 / 9.00$ & $3.3 \pm 0.30$ \\
\hline 3 & 57 & $\mathbf{M}$ & 10 & 6.94 & $5.6 \pm 0.70$ & $12.50 / 11.21$ & $5.8 \pm 0.65$ \\
\hline 4 & 57 & $\mathbf{M}$ & 10 & 6.67 & $4.3 \pm 0.50$ & $11.60 / 10.21$ & $4.7 \pm 0.48$ \\
\hline 5 & 52 & $\mathbf{M}$ & 14 & 7.22 & $8.7 \pm 0.77$ & $8.97 / 8.85$ & $8.9 \pm 0.79$ \\
\hline 6 & 52 & $\mathbf{M}$ & 7 & 6.94 & $4.2 \pm 0.39$ & $9.29 / 10.00$ & $3.7 \pm 0.37$ \\
\hline 7 & 55 & $\mathbf{M}$ & 2 & 5.83 & $3.7 \pm 0.34$ & $12.70 / 14.17$ & $3.6 \pm 0.51$ \\
\hline $\mathbf{M}$ & 53.1 & & 8.43 & 6.63 & 5.33 & & 5.52 \\
\hline SE & & & & & \pm 0.78 & & \pm 0.93 \\
\hline MD & & & & & & 0.19 & \\
\hline$\% \Delta$ & & & & & & 3.56 & \\
\hline$\underline{p}$ & & & & & & $>0.50$ & \\
\hline
\end{tabular}

M, Mean; FBS, Fasting blood sugar; FBF, Forearm blood flow; SE, Standard error; $\mathrm{MD}$, Mean difference; CV,C/T, Coefficient of variation, control/test; $\% \Delta$, percentage change. 

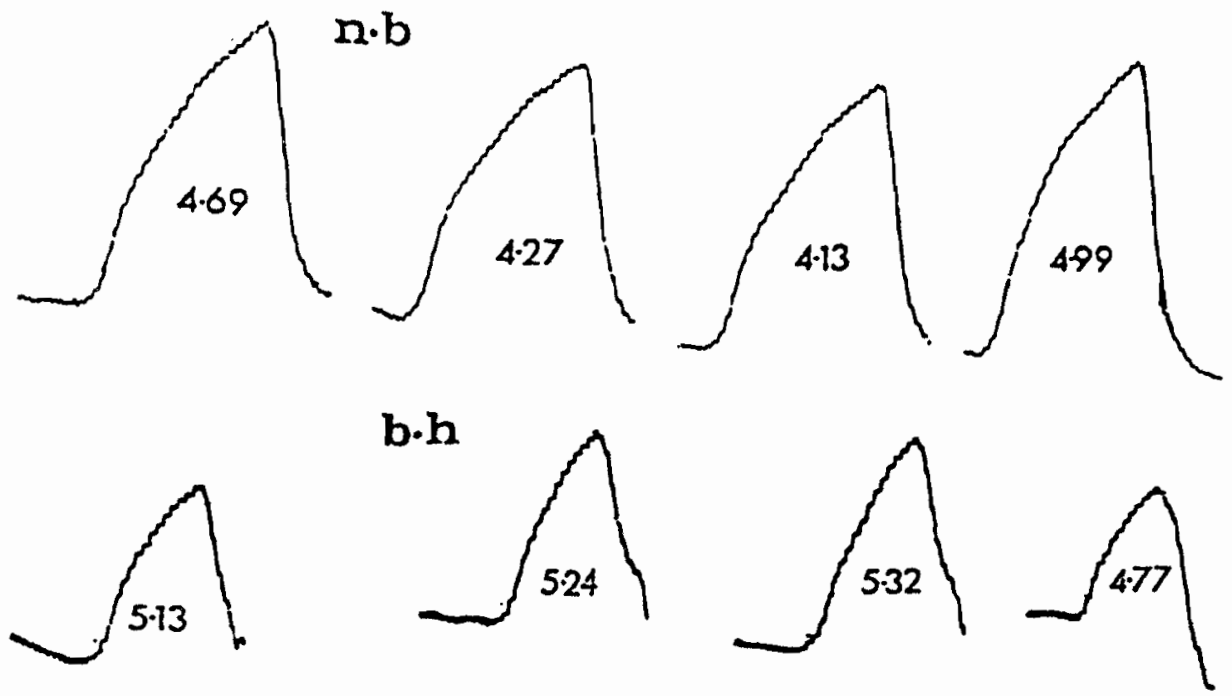

Fig. 2. Forearm inflow curves recorded in a diabetic patient with neuropathy while breathing normally (nb) and during the last 15 seconds of a 60 -second breath holding (bh) duration.

\section{DISCUSSION}

The forearm blood flow recorded during the voluntary arrest of breathing for $40-65$ seconds was significantly reduced in all control subjects (mean $\% \Delta=$ $-41.16, p<0.01)$. This response is probably a central effect resulting from the increase in $\mathrm{PaCO}_{2}$ and a decrease in $\mathrm{PaO}_{2}$ during breath holding. The decreased intrathoracic pressure and lung volume shrinkage occurring in the thorax during this testing condition probably augment the chemical changes (Mithoefer, 1959) that lead to reflex vasoconstriction.

Repeated forearm blood flow measurements made during breath holdings of 40-65 seconds in controls showed that different durations of breath holding in the range given appear to produce essentially the same effect on flow. It is also observed in several subjects that the forearm vasoconstricting responses occurring in about 35 seconds after the beginning of breath holding are essentially the same as the ones observed during a breath holding durations of 
40-65 seconds. This implies that flow response is not proportional to the duration of breath holding. Observations made by other workers show similar trends. Experimental findings by Agostoni (1963) show that an apnoea of 34-55 seconds produces an alveolar $\mathrm{PCO}_{2}$ rise of about $1.7 \mathrm{kpa}$ as compared with an alveolar $\mathrm{PCO}_{2}$ rise of $2.23 \mathrm{kpa}$ occurring during an apnoea of 76 seconds. Besides, the changes in $\mathrm{PaO}_{2}$ and $\mathrm{PaCO}_{2}$ observed by Paulev (1969) during breath holding durations of 60 and 150 seconds were not much different. Similar results were found by Dubois (1952) and by Dubois et al. (1952). The major part of the response to breath holding, therefore, seems to take place in the first 35-40 seconds. This is probably related to the quasi-exponential approach of $\mathrm{paCO}_{2}$ to mixed venous blood.

Forearm blood flow measurements recorded in diabetic neuropathy and matched for age and sex with the above control subjects showed no change in response to breath holding. There was no forearm blood flow response to breath holdings of $40-65$ seconds $(5.33 \pm 0.78 \mathrm{ml} / 100 \mathrm{ml} / \mathrm{min}$ and $5.52 \pm 0.93 \mathrm{ml} / 100 \mathrm{ml} / \mathrm{min}$, before and during breath holding, respectively). Diabetic patients with metabolic derangements (Gabbay et al., 1966; Gabbay and Snider, 1970) develop sympathetic denervation of blood vessels, vessel wall rigidity and atherosclerosis in skin and skeletal muscle (Bloodworth, 1963; Munck et al., 1966; Siperstein et al., 1968; Vracko, 1970; Eliasson, 1971; Ewing, 1978; Hilsted, 1978; Koltringer et al., 1992). These conditions apparently alter the blood supply to the CNS and the peripheral nerves (Elia and Kurpad, 1993) and to the blood vessels themselves. Resting peripheral blood flow in such patients is more than five fold the flow in normal controls (Archer et al., 1984; Gilbey et al., 1986). Studies made by Christensen (1970) and Hilsted (1978; 1981) showed a similar trend. The increase in resting blood flow reflects that the nutrient circulation is bypassed by arteriovenous shunts (Tooke et al., 1985). This increase in flow is a fixed increase in patients with severe neuropathy (Partsch, 1977). Besides, the skin temperature is increased in the neuropathic limb (Ward et al., 1983). All these factors are liable to obscure the effect of vascular thickening and rigidity on flow.

With the absence of the central reflex effect of the blood gases, a direct vasodilatory is expected to occur. This was not evident in the present investiga- 
tion $(\% \Delta=3.56, p>0.50)$. Blood vessels with damaged endothelium are not responsive to dilating agents (McVeigh et al., 1992; Williams et al., 1996; Avogaro et al., 1997). The lack of vasodilatation is, therefore, probably a reflection of the predominance of the lack or ineffectivity of endotheliumderived factors on which vasoactive substances like $\mathrm{CO}_{2}$ and $\mathrm{O}_{2}$ act to produce vasodilatation (Sharpey-Schafer, 1960; Daugherty et al., 1967; Didji, 1967; Eliasson, 1971). Other findings implying lack in the change of blood flow include impairment of vascular contraction and endothelium-dependent relaxation in diabetic neuropathy (Munck et al., 1966; Shimokawa et al., 1989; McNally et al., 1994). This means that a combination of factors may balance out the direct effect of increased $\mathrm{PaCO}_{2}$ and decreased $\mathrm{PaO}_{2}$ to produce a vasodilatation over and above the resting blood flow which is already elevated as a result of the aforementioned factors.

Another finding in the present study was that the duration of diabetes was not related to either the neurological changes or the increase in resting forearm blood flow of diabetics. This is in agreement with the observation made by Tooke et al. (1990) in which no correlation was observed between the duration of diabetes and capillary pressure, arterial blood pressure, prevailing blood glucose or skin temperature. Koltringer $e t$ al. (1992) also observed that there was no correlation between the duration of diabetes and the degree of neuropathy. Diabetic patients selected for this study had essentially the same problems despite the wide range of the duration of diabetes. This may be attributable to a number of factors including the degree of diabetes control and the individual variation in susceptibility to changes related to diabetes.

To sum up, the present study indicated that: (1) breath holding in normal controls induces reflex forearm vasoconstriction that is not proportional to the duration of breath holding; (2) resting mean forearm blood flow is higher in diabetic patients than in normal subjects probably due to metabolic changes, and structural damages in autonomic nerves and blood vessels ; (3) the duration of diabetes appears to have no proportionate effect in inducing neurovascular disorders; (4) using resting forearm blood flow and arterial blood pressure as testing variables, breath holding can be used as one of the quick methods for assessing autonomic denervation of blood vessels. 


\section{ACKNOWLEDGEMENTS}

The cooperation of both control subjects and diabetics to participate in the present study is very much appreciated. The pilot study I made on diabetic patients in the Department of Physiology, University of Dundee, UK, is also acknowledged.

\section{REFERENCES}

1. Agostoni, E. (1963). Diaphragm activity during breath holding: Factors related to its onset. J. Appl. Physiol. 18:30-36.

2. Archer, A.G., Roberts, V.C. and Watkins, P.J. (1984). Blood flow patterns in painful diabetic neuropathy. Diabetologia 27:563-567.

3. Avogaro, A., Piarulli, F., Valerio, A., Miola, M., Calveri, M., Pavan, P., Vicini, P., Cobelli, C., Tiengo, A., Calo, L. and Del-Prato, S. (1997). Forearm nitric oxide balance, vascular relaxation, and glucose metabolism in NIDDM patients. Diabetes 46(6):1040-1046.

4. Bloodworth, J. (1963). Diabetic Microangiopathy. Diabetes 12:99-114.

5. Christensen, N.J. (1970). A reversible vascular abnormality associated with diabetic ketosis. Clin Sci. 39:539-548.

6. Daugherty, R.M.Jr., Scott, J.B., Dabney, J.M. and Haddy, F.J. (1967). Local effects of $\mathrm{O}_{2}$ and $\mathrm{CO}_{2}$ on limb, renal and coronary vascular resistances. Am. J. Physiol. 213:1102-1110.

7. Didji, A. (1967). Local vasodilator action of $\mathrm{CO}_{2}$ on blood vessels of the hand. $J$. Appl. Physiol. 14:414-416.

8. Dubois, A.B., Britt, A.G. and Fenn, W.C. (1952). Alveolar $\mathrm{CO}_{2}$ during the respiratory cycle. J. Appl. Physiol. 4:535-548.

9. Dubois, A.B. (1952). Alveolar $\mathrm{CO}_{2}$ and $\mathrm{O}_{2}$ during breath holding, expiration and inspiration. J. Appl. Physiol. 5:1-12.

10. Elia, M. and Kurpad, A. (1993). What is the blood flow to resting human skeletal muscle? Clin. Sci. 84:559-563.

11. Eliasson, S.G. (1971). Disorders of the nervous system in diabetes. The Medical Clinics of North America 55(4):1001-1007. 
12. Ewing, D.J. (1978). Cardiovascular reflexes and Autonomic Neuropathy. Clin. Sci. and Mol. Med. 55:322-327.

13. Gabbay, K.H., Merola, L.O. and Field, R.A. (1966). Sorbitol pathway: presence in nerve and cord with substrate accumulation in diabetes. Science 151:209-221.

14. Gabbay, K.H and Snider, J.J. (1970). Galactosemic neuropathy. Diabetes 19:357-358.

15. Gilbey, S.G., Grenfell, A., Edmonds, M.E., Archer, A. and Watkins, P.J. (1986). Peripheral blood flow in diabetic patients with end-stage renal failure. In: Clinics in Endocrinology and Metabolism Long Term Complications of Diabetes, Transplantation Proceedings. Vol. 15 no. 4, p. 797 (Watkins, P.J., ed.) W.B. Saunders Company, London, Philadelphia, Toronto.

16. Godfrey, S. and Campell, F.J.M. (1968). The control of breath holding. Resp. Physiol. 5:385-400.

17. Hilsted, J. (1978). Decreased vasomotor tone in diabetic orthostatic hypotension. Diabetes 28:970-973.

18. Hilsted, J. (1981). Hormonal, metabolic and cardiovascular responses to hypoglycaemia in diabetic autonomic neuropathy. Diabetes 30:627-633.

19. Ketty, S.S. and Schmidt, C.F. (1948). The effects of altered arterial tensions of $\mathrm{CO}_{2}$ and $\mathrm{O}_{2}$ on cerebral oxygen consumption of normal young men. J. Clin. Invest. 27:484-492.

20. Kontos, H.A., Richardson, D.W. and Patterson, J.L.Jr. (1967). Effects of hypercapnia on human forearm blood vessels. Am. J. physiol. 212: 1070-1080.

21. Koltringer, P., Langsteger, W., Lind, P., Klima, G., Wakonig, P., Eber, O. and Reisecker, F. (1992). Autonomic neuropathies in skin and its incidence in NIDDM. Hormone and metabolic Research Supplement 26:87-89.

22. Lennox, W.G. and Gibbs, E.L. (1932). The blood flow in the brain and leg of man and the changes induced by alteration of blood gases. J. Clin. Invest. 11:1155-1177.

23. Lioy, F., Blinkhorn, M.T. and Garneau, C. (1985). Regional haemodynamic effects of changes in $\mathrm{PaCO}_{2}$ in the vagotomized, sino-aortic de-afferented rat. Journal of the Autonomic Nervous System 12(4):301-313.

24. Lopez de Pablo, A.L., Gonzalez, M.C., Dieguez, G., Gomez, B. and Lluch, S. (1982). Reduction of cerebrovascular reactivity during hypercapnia. Am. J. Physiol. 242(5):441-446. 
25. McNally, P.G., Watt, P.A.C., Rimmer, T., Burden, A.C., Hearnshaw, J.R. and Thurston, H. (1994). Impaired contraction and endothelium-dependent relaxation in isolated resistance vessels from patients with IDDM. Clin. Sci. 87:31-36.

26. McVeigh, G.E., Brennan, G.M., Johnston, G.D., McDermott, B.J., McGrath, L.T., Henry, W.R., Andrews, J.W. and Heys, J.R. (1992). Impaired endothelium-dependent vasodilatation in patients with type 2 (non-insulin dependent) diabetes mellitus. Diabetologia 35(8):771-776.

27. Mithoefer, J.C. (1959). Mechanism of pulmonary gas exchange and $\mathrm{CO}_{2}$ transport during breath holding. J. Appl. Physiol. 14(5):706-710.

28. Moorhouse, J.A., Carter, S.A. and Doupe, J. (1968). Vascular responses in diabetic peripheral neuropathy. Brit. Med. J. 1:883-888.

29. Munck, O., Lindbjerg, Ib.F., Binder, C., Lassen, N.A. and Trap-Jensen, J. (1966). Skeletal muscle blood flow in diabetic patients. Diabetes 15(5):323-326.

30. Parving, H.H. (1983). Genesis of Microangiopathy. Diabetes Metabolism 32:943-948.

31. Partsch, H. (1977). Neuropathies of the ulcero-multilating types. Clinical aspects, classification circulation measurements. In: Clinics in Endocrinology and Metabolism Long Term Complications of Diabetes. Vol. 15 no. 4, p. 891 (Watkins, P.J., ed.) W.B Saunders Company, London, Philadelphia, Toronto.

32. Paulev, P.E. (1969). Respiratory and cardiovascular effects of breath holding. Acta Physiol. Scand. 324 (Supplement):83-99.

33. Rose, C.E. Jr., Althaus, J.A., Kaiser, D.L., Miller, E.D., and Carey, R.M. (1983). Acute hypoxemia and hypercapnia: increase in plasma catecholamines in conscious dogs. Am. J. Physiol. 245(6):H924-929.

34. Sharpey-Schafer, E.P. (1960). Circulatory reflexes in chronic disease of the afferent nervous system. J. Physiol. 134:1-10.

35. Shimokawa, H., Flavahan, N.A. and Vanhoutte, P.M. (1989). Natural course of the impairment of endothelium-dependent relaxations after balloon endothelium removal in porcine coronary arteries. Possible dysfunction of a pertussis toxinsensitive G. protein. Circ. Res. 65:740-753.

36. Singh, P.I. and Khurana, I. (1990). Decreased tolerance to orthostatic stress. Indian J. Med. Sci. 44(10):273-280. 
37. Siperstein, M.D., Unger, R.N. and Madison, L.L. (1968). Studies of muscle capillary basement membrane in normal subjects, diabetics and prediabetic patients. J. Clin. Invest. 47:1973-1999.

38. Tooke, J.E., Lins, P.E., Otergren, J., Adamson, V. and Fagrell, B. (1985). Effects of intravenous insulin infusion on skin microcirculatory flow in type I diabetes. In: Clinics in Endocrinology and Metabolism - Long term Complications of Diabetes. Vol 15 no. 4, p. 893 (Watkins, P.J., ed.) W.B. Saunders Company, London, Philadelphia, Toronto.

39. Tooke, J.E., Sandman, D.E. and Shore, A.C. (1990). Capillary pressure in the peripheral circulation in health and diabetes. Proceedings of Physiological Society, J. Physiol. (Supplement) 6-7.

40. Vracko, R. (1970). Skeletal muscle capillaries in diabetics. A quantitative analysis. Circ. 41:271-283.

41. Ward, J.D., Simms, J.M., Knight, G., Boulton, A.J.M and Sandler, D.A. (1983). Venous distension in the diabetic neuropathic foot (physical sign of arteriovenous shunting). Journal of the Royal Society of Medicine 76:1011-1014.

42. Whitney, R.J. (1953). The measurement of volume changes in human limbs. $J$ Physiol. 121:1-27.

43. Williams, S.B., Cuso, J.A., Roddy, M.A., Johnstone, M.T. and Creager, M.A. (1996). Impaired nitric oxide-mediated vasodilatation in patients with non-insulindependent diabetes mellitus. J. Am. Coll. Cardiol. 27(3):567-574.

44. Zhang, T.X., Rohliceck, CV., Polosa, C. (1982). Responses of sympathetic preganglionic neurones to systemic hypercapnia in the acute spinal cat. Journal of the Autonomic Nervous System 6(3):381-389. 